\title{
Краудсорсинговые площадки региональных и муниципальных органов власти
}

\author{
О. Е. Комаров, А. В. Соколов \\ Ярославский государственный университет имени П.Г. Демидова \\ oleg93komarov@mail.ru, alex8119@mail.ru
}

\section{Аннотация}

В современных реалиях возрастает необходимость выстраивания диалога между властью и гражданским обществом, увеличения степени участия граждан в управленческо-государственной деятельности. Оптимальным каналом выстраивания подобного взаимодействия является Интернет. Особую роль в рамках этого взаимодействия могут играть краудсорсинговые платформы, которые позволяют демонстрировать интересы общества, выявлять и оперативно решать существующие проблемы, а также способствовать вовлечению граждан в процесс подготовки и принятия решений. Авторами сформирована система критериев оценки данных площадок, позволяющая выявить особенности их функционирования и оценить результативность. Среди критериев можно отметить функциональность краудсорсинговой площадки, ее посещаемость и активность использования, возможность ранжирования пользователей, степень интерактивности и др. Также в статье представлен анализ крупнейших региональных площадок, ориентированных на демонстрацию гражданами наиболее актуальных для них проблем. Авторами представлена оценка результатов работы органов власти с предложениями граждан.

Ключевые слова: краудсорсинг, региональные и местные органы власти, проект, коммуникация, инициативы, обращения, Интернет

Библиографическая ссылка: Комаров О.Е., Соколов А.В. Краудсорсинговые площадки региональных и муниципальных органов власти // Государство и граждане в электронной среде. Выпуск 4 (Труды XXIII Международной объединенной научной конференции «Интернет и современное общество», IMS-2020, Санкт-Петербург, 17 - 20 июня 2020 г. Сборник научных статей). - СПб: Университет ИТМО, 2020. C. $73-85$. DOI: 10.17586/2541-979X-4-73-85

\section{1. Введение}

Вызовы и возможности, которые стоят перед современным обществом, во многом обусловлены тем, что объём и масштаб задач, стоящих перед различными акторами политической и общественной жизни, не позволяют им опираться только на собственные силы и решать существующие проблемы самостоятельно. Демократизация и укрепление политической жизни в современных реалиях прочно взаимосвязана с развитием политической коммуникации и появлением её новых форматов. Ведущей тенденцией является усиление политического дискурса посредством его виртуализации и использования новых информационно-коммуникационных технологий.

Общественность выражает и формулирует свои настроения, применяя при этом существующие возможности современных инструментов коммуникации, а власть, в лице муниципальных и региональных органов власти, стремится корректировать свои действия на основе обратной связи. 
Происходит коммуникативная коллаборация власти и общественности, что, в конечном счёте, позволяет снизить социальное напряжение и содействует демобилизации, приводит к снижению вовлеченности граждан в протесты.

Ocобое значение в рамках данных процессов играет применение современных информационных технологий, активная реализация проектов в рамках сети Интернет, поэтому возрастает роль такой технологии, как краудсорсинг. Данный инструмент уже успел получить в широкое распространение в мировой практике, являясь новым форматом взаимодействия субъектов в рамках инновационной деятельности и включения. Краудсорсинг сегодня все чаще используется как новый метод вовлечения общественности в политический процесс [1].

\section{2. Теоретические подходы}

Краудсорсинг представляет собой один из взаимных межличностных коммуникационных форматов. Краудсорсинг - это привлечение человеческого потенциала для совместного решения определенных вопросов или реализации проектов. При помощи краудсорсинга определённый вид работы осуществляется совместными усилиями, а запланированная идея становится реализованной обычными людьми. Краудсорсинг является новым форматом общественно-политического диалога, где его основными характеристиками можно определить:

1) значительное количество добровольцев, участвующих в коммуникативном процессе;

2) использование виртуальных сетей, которые позволяют оптимизировать расходы на поиск, сбор и обработку информации;

3) координация действий участников диалога, обсуждение способов решения проблем и добровольное присоединение к сообществам;

4) дешевый и быстрый инструмент работы с информацией.

М. Вукович изучал краудсорсинг в рамках структурно-функционального подхода. Он выделяет в качестве характерной черты краудсорсинга разделение и детализацию процедур. Вне зависимости от количества и сложности существующих задач каждая из них может быть разделена на условные подзадачи, выполнением которых может заняться всего один участник краудсорсинга [2]. Из его позиции становится очевидным то, что возможно решение практически любой задачи, достаточно лишь провести её дифференциацию на подзадачи для участников краудсорсинга. Краудсорсинг также можно рассматривать в качестве технологии, объединяющей субъектов экономического пространства. К сторонникам финансово-экономического подхода следует отнести В. Каппусвами. В рамках данного подхода главным ресурсом взаимоотношений участников являются финансы. Между участниками происходит обмен финансовых средств на какие-либо материальные подарки, бонусы. Одна из сторон краудсорсинга выступает в качестве спонсора реализации идей и решений другой стороны [3].

Изучение применения данной технологии вызывает интерес, как у зарубежных, так и российских учёных. О.В. Быхтин изучал краудсорсинг через призму мотивационных факторов, которые определяют участие граждан в его реализации [4]. В результате проведенного в Белгородской области исследования им было выявлено, что определяющими мотивами интеграции граждан в краудсорсинг являются участие в чём-то важном для общества и для себя, материальная выгода, возможность самореализации. С.В. Лобова и Р.А. Долженко через изучение типологий и функций регионального краудсорсинга разработали показатели результативности его применения [5]. И.В. Мирошниченко рассматривает краудсорсинг как форму взаимодействия сетевого гражданского общества и органов власти, которая способствует модернизации государства. Также в качестве одного из определяющих факторов участия граждан в реализации в краудсорсинговом проекте она определяет интерес граждан увидеть реализацию предложенных идей в публичной практике [6]. 
В.А. Сапрыка изучал краудсорсинг через описание его функций. Он выделил 7 наиболее важных функций краудсорсинга: информационную, контрольную, исследовательскую, обучающую, коммуникативную, функцию легитимации и инновационную [7]. Г.Н. Гайдукова через анализ барьеров участия в краудсорсинге приходит к выводам, что в системе государственного управления широкая реализация краудсорсингового потенциала невозможна [8].

В.В. Буровым, Е.Д. Патаракиным и Б.Б. Ярмахиным был изучен краудсорсинг в качестве технологии доработки нормативно-правовых актов [9]. Ими была предложена ранее апробированная функциональная схема сообщества, в рамках которого организована деятельность по улучшению отдельных статей и глав законодательного текста. Действия заинтересованных участников краудсорсинга основываются на базисе общего смыслового объекта. Т.А. Нестик рассмотрел краудсорсинг через призму его психологических особенностей. Краудсорсинг он определил, как технологию разработки решений и прогнозирования будущего [10].

Рассматривая феномен краудсорсинга, нельзя не отметить работу российского исследователя Е.Б. Когана, который изучает краудсорсинг через фактор репутации. По его мнению, репутационный менеджмент заключается в необходимости создания открытой информационной среды для решения проблем, существующих у социальных субъектов. Краудсорсинг может выступать в данном случае как технология взаимодействия с аудиторией, фактора поднятия собственного имиджа. Данный подход наиболее актуален для органов управления и власти, для которых задача создания и поддержания собственного имиджа является одной из ключевых. Традиционные механизмы в данном случае значительно уступают и являются менее эффективными по отношению к представленным возможностям краудсорсинга. Коган также учитывает тот факт, что краудсорсинг выступает не только как фактор мотивации краудсорсинга, но и как инструмент формирования имиджа субъекта [11].

Также необходимо отметить, что в авторском понимании краудсорсинг допустимо считать формой электронного участия граждан. Понятие «электронное участие» представляет собой взаимодействие органов власти с населением при помощи существующих электронных технологий и сети Интернет. Как отмечает А.В. Чугунов, электронное участие обеспечивает взаимодействие органов власти и населения «с целью учёта мнения граждан при принятии политических и управленческих решений» [12]. Инициаторами данного взаимодействия выступают, как правило, активные граждане, стремящиеся оказать непосредственное влияние на политический процесс. При этом также стоит обратить внимание на существующие краудсорсинговые платформы, в рамках которых участники предоставляют возможность взаимодействия с органами власти и решения конкретных проблем. На данных платформах население имеет возможность подавать различного рода обращения, «жалобы». Учитывая общую цель данных проектов - улучшение качества жизни города или области, можно рассматривать данные «жалобы» как идеи, описывающие то, что именно необходимо исправить для достижения данной цели. В соответствии с этим, на подобных площадках происходит генерация идей неограниченным кругом лиц для достижения общей цели участников, а, значит, данные площадки допустимо относить к краудсорсинговым. В связи с этим А.В. Чугунов отмечает, что электронное участие «предполагает широкое вовлечение граждан и структур гражданского к управлению и развитие методов учёта общественного мнения и краудсорсинга», что, в свою очередь, также подтверждает тезис, что краудсорсинг можно считать формой или технологией электронного участия [13].

Таким образом, краудсорсинг является распространенным интеллектуальным процессом коммуникации большого числа людей, незнакомых друг с другом, по общей задаче в сетевой среде. Реализация на практике подобных технологий диалога жителей регионов с властью особенно актуальна в условиях, выдвинутых Президентом России Владимиром Путиным стратегических инициатив. 
Также в начале 2020 года им было выдвинуто требование создания платформ прямой коммуникации во всех регионах России, что обусловлено возможностью в режиме «онлайн» реагировать на повседневные проблемы граждан в кратчайшие сроки, значительно эффективнее решать существующие проблемы. Президент России добавил, что на основе анализа лучших практик необходимо реализовывать подобные инициативы [14].

\section{3. Методика исследования}

Целью данного исследования является выявление особенностей функционирования краудсорсинговых площадок органов управления и выработка рекомендаций, позволяющих увеличить результативность и оперативность применения краудсорсинга в процессе управления региональных и местных властей.

Изучая особенности краудсорсинга как инструмента диалога власти и общества, особое значение имеют практические результаты функционирования платформ, где данная технология активно используется. Оценить степень результативности функционирования и реализации на практике краудсорсинговых проектов можно по различным показателям. Авторами настоящего исследования было принято решение о том, что наиболее значимыми и качественными показателями функционирования краудсорсинговых платформ в деятельности региональных и муниципальных органов власти являются:

- посещаемость и активность пользователей (общее количество участников проектов; общее число поданных обращений/идей; количество решенных проблем; вовлечённость в проект жителей региона);

- интерактивность и оформление портала (количество категорий обращений; наличие карты событий; отображение исполнителя обращения; наличие инструкции пользования порталом; наличие возможности добавления к обращению фотографии о проблеме);

- функциональные возможности портала (количество категорий обращений; наличие возможности для анонимных обращений; наличие рейтинга обращений; необходимость предварительной регистрации или авторизации для подачи заявления; наличие необходимости подтверждения достоверности указанных данных о заявителе; наличие приложений на мобильные устройства; возможность комментирования обращения неавторизованными пользователями; возможность блокировки пользователей);

- меры контроля для пользователей (количество дней, необходимых для предоставления ответа заявителю; наличие контроля заявителя; необходимость (наличие) фотоотчёта выявленной проблемы заявителя; возможность оценки качества принятого решения; наличие возможности отправить обращение на доработку);

- ранжирование пользователей (наличие рейтингов заявителей; наличие рейтинга исполнителей обращений);

- мотивация и меры дополнительной поддержки (наличие условных «благодарностей» заявителям; наличие возможности поддержать идею/предложению/ проблему);

- иные особенности функционирования проекта (создатели, спонсоры, инициаторы проекта; длительность существования проекта; наличие возможности передачи идеи или предложения не через Интернет; наличие функционирующей обратной связи с кураторами проекта; наличие закрытых обращений, исполнение которых формально не завершено).

Выбор данных показателей обусловлен функциональными особенностями краудсорсинга, итогами операционализации термина «краудсорсинг», приведшей к выявлению его ключевых характеристик, а также необходимостью изучения особенностей протекания коммуникации на краудсорсинговых площадках в органах власти. По данным показателям были проанализированы 10 краудсорсинговых площадок: «Делаем вместе!» (Ярославская область) [15]; «Открытая Казань» [16]; Добродел (Московская область) [17]; «Сделай Орёл лучше (Орловская области)» [18]; «Активный гражданин республики Бурятия» [19]; Портал «Наш Санкт-Петербург» [20]; «Народная экспертиза (Белгородская 
область)» [21]; «Открытый регион Хабаровского края» [22]; «Действуем вместе» (Курская область) [23]; «Наш дом - Рязань» [24].

Выбор пал именно на данные порталы ввиду их относительно высокой активности, данные порталы функционируют в настоящее время. Изучение инструментов краудсорсинга на практике в рамках данных порталов позволит представить общую картину развития краудсорсинга в региональных и местных органах власти, а также характерные особенности и ключевые показатели. Также выбор данных платформ был обусловлен возможностью изучить и оценить функционирование краудсорсинга на разных территориях с отличающей численностью населения, в разных федеральных округах Российской Федерации. Нельзя не отметить то, что процесс поиска наличия функционирующих краудсорсинговых порталов в регионах был осложнён низким уровнем информационной поддержки со стороны органов власти, что также, во многом, определило выбор анализируемых объектов. В частности, на официальных порталах большинства субъектов отсутствует информация о наличии функционирующих краудсорсинговых проектаов, в СМИ данная информация публикуется крайне редко, что осложняет работу не только исследователей краудсорсинга, но и снижает количество привлекаемых участников.

Также в рамках данного исследования для выявления характерных особенностей процесса коммуникации был проведен анализ непосредственно представленных обращений. Для изучения качественных и количественных характеристик были выбраны обращения, представленные на порталах за 2019 год, с системной выборкой - каждое последнее обращение дня, присланное в кратные числу 3 дни (3, 6, 9, 12 и т.д., за исключением февраля). В феврале, ввиду отсутствия 30 дней, был проведён анализ обращений, присланных 27 и 28 числа. Данный шаг выборки позволил выявить особенности представленных обращений по временным параметрам, выявить закономерности тематики и качества исполнения, отследить динамику обращений по количественным и качественным показателям за относительно небольшой промежуток времени. Всего суммарно было проанализировано 360 обращений 3-х порталов: «Делаем вместе!», «Добродел», «Наш Санкт-Петербург». Выбор данных портал был обусловлен тем, что на них наблюдается максимальная активность участников среди анализируемых порталов, что позволило составить общую картину о представленных обращениях и особенности функционирования порталов в целом.

\section{4. Особенности функционирования краудсорсинговых площадок региональных и муниципальных органов власти}

Суммарное количество участников анализируемых проектов составляет 1852531 . Это относительно высокий уровень привлечённых пользователей, однако, нельзя не отметить тот факт, что данные по числу пользователей представлены только на 6 из 10 платформ. При этом, суммарный показатель числа участников сформирован, в основном, за счёт лишь 1 проекта («Добродел» Московская область), что можно объяснить общей численностью данного региона, значительно превышающей другие. В остальных порталах численность участников примерно одинаковая, которая составляет в среднем около 20000 участников на проект. Средняя вовлечённость жителей регионов в работу анализируемых проектов составляет порядка 5\%, что, относительно немного, учитывая тот факт, что вовлечённость в Московской и Белгородской областях составляет порядка $23 \%$, а в остальных регионах не превышает 1,2\%. Проблема низкой вовлечённости населения в процесс функционирования краудсорсинговых порталов, можно предположить, обоснована низким уровнем информированности граждан о самом наличии подобных проектов.

Общее число представленных обращений составляет 8187387 . Основное количество их них подано на платформы «Добродел» и «Наш Санкт-Петербург», что также объясняется общей численностей жителей в данных субъектах Российской Федерации. Из 
них почти 70\% (5 710 952) представляют собой обращения с указанием на наличие проблемы. Из суммарного числа опубликованных обращений 5864046 были закрыты или решены, что составляет почти $72 \%$. Однако, указанная цифра не может в полной мере отражать существующую картину результативности данных проектов ввиду того, что в каждом из 10 представленных проектов были обнаружены закрытые/исполненные обращения, исполнение которых фактически не завершено. Получается, что для данных проектов характерна такая проблема, как наличие искусственно закрытых проблем. Это, зачастую, происходит по причине автоматического закрытия обращения по истечению срока принятия/непринятия ответа заявителем или ответ исполнителя носит формальный характер, не отвечает по существу на поставленный в сообщении вопрос, и никаких действий со стороны исполнителя в направлении решения проблемы предпринято не было.

В целом, данные проекты обладают высокими функциональными и интерактивными показателями. У 100\% анализируемых проектов имеется карта событий, что позволяет наглядным образом увидеть существующие проблемы в конкретном округе или районе и наблюдать процесс решения в режиме «онлайн». Пользователи данных проектов имеют возможность своевременно узнавать об исполнителе поставленной задачи, что увеличивает возможности контроля со стороны заявителя и степень ответственности исполнителя. Также на всех представленных проектах существует относительно равномерная дифференциация обращений по категориям: средний показатель составляет 13,7. Большое количество категорий позволяет классифицировать обращения по определённым параметрам, что в дальнейшем помогает исполнителю понимать сущность представленной проблемы, в более сжатые сроки и результативнее решать задачу. К сожалению, обратная связь работает не на всех представленных платформах. В адрес всех площадок были направлены письма с рекомендациями и вопросами, но ответы были получены лишь от 4-х площадок, а именно от порталов «Добродел», «Наш Санкт-Петербург», «Действуем вместе», «Наш дом - Рязань». Отсутствие обратной связи лишает возможности кураторов проектов получать актуальную информацию от пользователей о возможностях изменения работы порталов в лучшую сторону и существующих недочётах.

У 8 из 10 проектов присутствует инструкция пользования порталом, что также позволяет неопытным или начинающим пользователям максимально продуктивно пользоваться всеми возможностями данных проектов для решения существующих проблем. Наличие возможности приложить к обращению фотографии или документы, подтверждающие факт наличия проблемы, также значительно повышают время и скорость поиска и обработки полученной информации исполнителем. В 8 из 10 случаев есть возможность загрузки приложений данных порталов на мобильные устройства, что позволяет пользователям вне зависимости от местоположения и времени суток участвовать в процессе функционирования портала. В половине анализируемых проектов присутствуют ссылки на аналогичные группы в социальных сетях. Это является большим плюсом, так как способствует дополнительной возможности привлечения новых участников, создаёт дополнительные площадки для информирования населения о сущности и изменениях функционирования порталов.

Перед началом активной работы на всех порталах необходимо пройти процедуру регистрации или авторизации, что способствует обеспечению отсеивания определённой категории обращений (спам, реклама и пр.). При этом, нельзя не отметить, что на 2-х представленных необходимо подтверждение достоверности указанных данных об участнике, в частности, через Госуслуги, что делает систему фильтрации ещё более строгой. На других же порталах существует возможность указания недостоверных данных, что фактически при желании заявителя делает обращения анонимными, что наталкивает на мысль о возможности получения обращений по несуществующим проблемам, снижая оперативность отбора и обработки полученной информации исполнителем. Возможность комментирования незарегистрированным/неавторизованным пользователям имеется лишь на одном портале. Наличие у 7 из 10 порталов присваивания 
регистрационных номеров позволяет пользователям в кратчайшие сроки найти собственные обращения, отследив динамику принятых по ним решений.

Важным аспектом результативности порталов является наличие контроля заявителей над процессом принятия решения по существующим проблемам. Наличие мер контроля позволяет увеличить степень доверия по отношению к исполнителю, определить и оперативно представить исполнителю информацию об объёме, глубине выполненных работ. Наличие возможности подтверждения невыполненных работ провоцируют существенные, а не тривиальные изменения. Общие меры контроля имеются в 8 из 10 представленных проектах, но куда более показателен тот факт, что возможность отправить обращение на доработку, если исполнение обращения заявителя устраивает не в полной мере, присутствует на 7 площадках. И лишь в 3 проектах присутствует возможность оценки качества принятого решения, что ограничивает функциональный потенциал для пользователей.

Также важным показателем функциональных возможностей порталов следует отметить наличие ранжирования как пользователей, так и исполнителей. Рейтинг заявителей даёт возможность выявить наиболее активных пользователей портала и дополнительную мотивацию участникам выйти на лидирующие позиции. Это предоставляет дополнительные соревновательные стимулы, формирует стремление участников стать лучше других и занять место лидера. Данный рейтинг имеется лишь на 6 из 10 площадках, что является относительно низким показателем. Рейтинг исполнителей имеется также на 6 площадках. Он позволяет наглядно продемонстрировать то, как исполнители относятся к возложенным на них обязанностям, повышает чувство их персональной ответственности за решение поставленных задач, данный рейтинг является дополнительным стимулом к качественному и своевременному решению задач исполнителями.

Участие пользователей в деятельности проектов основано на факторах нематериальной мотивации. В основном, краудсорсинг строится на базисе сознания принятия участия в чём-то важном для общества и себя. Также определяющую роль играют нравственные стимулы, способствующие возникновению желания проявления собственных талантов для улучшения качества жизни и общества в целом [4]. Но при всём этом, развитие краудсорсинга требует включения новых дополнительных факторов мотивации. Касательно исследуемых порталов, нельзя не отметить, что в 2-х из 4 проектах используется поощрение самых активных участников призами и грамотами. Также на 4-х площадках существует возможность поддержать инициативу участника, что также является несомненной поддержкой инициативы.

Анализируемые порталы начали своё существование в разное время, некоторые из них реализуются уже почти 10 лет. Однако 4 из 10 возникли менее 2-х лет назад, что наглядно демонстрирует то, что органы власти в настоящее время стремятся внедрить краудсорсинг в управление регионами. Интересным фактом является то, что дизайн и структура некоторых сайтов в разных регионах идентичная. Разработкой данных порталов занимались либо одни разработчики, либо создатели нового сайта учитывали опыт предыдущих порталов, что носит позитивный характер. Также интересным наблюдением является персонализация порталов относительно глав субъектов Российской Федерации. Практически на всех проектах в графе информации сделан особый акцент на поддержке портала губернатором региона или мэром города, что позволяет сделать вывод о применении краудсорсингового проекта как инструмента формирования имиджа власти.

\section{5. Особенности обращений в краудсорсинговых площадках региональных и муниципальных органов власти}

Результаты анализа обращений также позволили сформулировать ряд выводов. Всего проанализированные обращения на данных порталах можно разделить на 36 тематических 
категорий. Тематика самых популярных тематик среди участников наглядно отображена в таблице (см. табл. 1).

Таблица 1. Самые популярные тематики обращений краудсорсинговых площадках

\begin{tabular}{|l|c|c|c|}
\hline \multicolumn{1}{|c|}{ Тематика обращений } & $\begin{array}{c}\text { Общее } \\
\text { количество } \\
\text { обращений }\end{array}$ & $\begin{array}{c}\text { Прощент от } \\
\text { суммарного } \\
\text { числа обращений }\end{array}$ & $\begin{array}{c}\text { Общее число } \\
\text { исполненных } \\
\text { обращений }\end{array}$ \\
\hline Ямочный ремонт & 40 & 11,1 & 22 \\
Общественный транспорт & 22 & 6,1 & 15 \\
Содержание контейнерных & 29 & 8,0 & 28 \\
площадок & 39 & 10,8 & 37 \\
Уборка двора & 39 & 10,8 & 34 \\
Освещение & 22 & 6,1 & 20 \\
Уборка подъезда & 27 & 7,5 & 27 \\
Информационные и рекламные & 20 & 5,5 & 16 \\
таблички и конструкции & \multicolumn{2}{|}{} \\
Свалка & \multicolumn{2}{|c}{} \\
\hline
\end{tabular}

Обращения участников проектов неравномерно распределены по тематикам, суммарное количество обращений на темы ямочного ремонта, общественного транспорта, уборки территории и освещения имеют значительный перевес относительно других тем. Их суммарное количество равняется 238 шт., что составляет примерно $66 \%$. Стопроцентный показатель выполнения работ имеют обращения по тематике освещения.

Из представленных обращений фактическое выполнение имеют 310 , что составляет около 86\% от общего числа: из них на портале «Делаем вместе!» выполнено 87 обращений (72,5\%), «Добродел» - 114 обращений (95\%), «Наш Санкт-Петербург» - 109 (90,8\%). Это относительно хороший показатель результатов деятельности данных проектов, что позволяет сделать вывод о том, что работа в рамках портала ведётся активно, а главные результаты - решение существующих проблем - планомерно достигаются.

На портале «Делаем вместе» средний срок исполнения обращения составляет 10,78 дней, на «Доброделе» - 6,64 дней, «Наш Санкт-Петербург»- 21,18. Средний показатель составляет 12,8 дней, что демонстрирует относительно высокий уровень оперативности принятых решений. Однако, нельзя не отметить то, что срок выполнения напрямую зависит от тематики обращения, что напрямую влияет на его сложность. В частности, решение вопросов, касающихся ямочного ремонта, занимает больше времени, нежели проблемы с освещением и общественным транспортом.

В связи с этим необходимо наличие классификатора, который дифференцирует необходимый срок исполнения обращений в зависимости от категории и сложности выполнения работ. Это позволит заявителям сформировать понимание о сроках ожидания выполненных работ, а исполнителю даст понимание о временном лимите исполнения обращений.

Суммарное количество просмотров на 3-х порталах составляет 2345. При этом количество просмотров на портале «Наш Санкт-Петербург» не отображается, имеется лишь указание на количество людей, поддержавших то или иное обращения. Наибольшее количество просмотров в обращениях, тема которых ямочный ремонт, уборка дворов и освещения.

В основном, представленные обращения носят цель решения общественных проблем, доля личных обращений составляет $6,11 \%$ (22 шт.). Личные обращения связаны с работой общественного транспорта и оплатой ЖКХ. Также анализируемые обращения носят в большей степени внесезонный характер - 341 из 360. Те обращения, которые носят сезонный характер, относятся к категории уборки дорог от снега и наледи, обрезки и опиловки деревьев и кустарников, отопления жилых помещений. 
Наличие фотоотчёта исполнения обращений и фотоотчёта, подтверждающего наличие проблемы, позволяет максимально оперативно предпринимать меры для устранения существующей проблемы и является подтверждением выполненных работ. Анализ показал, что на представленных порталах количество обращений, в которых имеется фотоотчёт исполнения обращений, составляет 205 из 360. Количество обращений заявителей с фотоотчётом наличия проблемы составляет 327 из 360, что также является положительной тенденций. Также дополнительным инструментом подтверждения факта исполнения работ является наличие подписанного представителем органом власти документа (письма). Суммарное количество обращений с подтверждающими подписанными документами составляет 176.

Важным инструментом контроля является возможность отправки сообщения на доработку в случаях, если качество выполнения работ не устраивает заявителя. Количество подобных случаев на порталах составляет 34. Из них в 19 случаях заявителю удалось добиться фактического исполнения обращения, а в 15 - нет.

\section{6. Заключение}

Анализ представленных краудсорсинговых проектов показал относительно высокие показатели развития. По $86 \%$ представленных «жалоб» заявителей были приняты положительные решения, существующие проблемы планомерно решаются органами власти. Работа по сбору информации и принятию решения на порталах организована оперативно, существуют незначительные проблемы обработки информации, касающейся определённых категорий проблем. На представленных площадках внедрены системы рейтингования пользователей, что в значительной степени повышает чувство персональной ответственности и является дополнительным стимулом к качественному решению задач, а также активности пользователей.

При выявленном комплексе положительных тенденций развития краудсорсинговых площадок, нельзя не отметить выявленные недостатки и барьеры. В частности, для проектов характерны проблема низкой вовлеченности граждан и наличие искусственно закрытых обращений. Отсутствие обратной связи не позволяет кураторам выстраивать максимально результативный диалог с участниками. Ограничивает функционал площадок и отсутствие возможности оценки качества принятого решения, что является дополнительной мерой контроля.

В целом, оценивая результаты применения краудсорсинга в органах власти, можно отметить положительную тенденцию их развития, доля выполненных обращений достаточно большая. Однако авторами подготовлены рекомендации, которые позволят более продуктивно применять данную технологию, что сделает реализацию данных проектов более результативной, функциональной и интерактивной:

- внедрить в работу порталов классификатор обращений по времени выполнения обращений в зависимости от сложности и тематики проблемы.

- организовать работу обратной связи, позволяющей получать предложения и жалобы по организации работы порталов;

- увеличить уровень информационной поддержки порталов со стороны органов власти, провести рекламную кампанию в СМИ и сети Интернет;

- исключить возможность автоматического закрытия обращений и присваивания им статуса «исполнено», что позволит повысить уровень доверия жителей к работе портала и к органам власти в целом;

- максимально дифференцировать категории по тематике, что в дальнейшем позволит исполнителю в более сжатые сроки и результативнее решать поставленную задачу;

- создать аналогичные порталу группы в социальных сетях и приложения на мобильные устройства, что позволит увеличить количество участников и повысит уровень функциональных возможностей пользователей; 
- организовать процедуру регистрации или авторизации, что способствует обеспечению отсеивания определённой категории неконструктивных пользователей;

- подготовить и разместить на сайте инструкцию пользования порталом, что позволит неопытным или начинающим пользователям максимально продуктивно пользоваться всеми возможностями данных проектов для решения существующих проблем;

- создать возможность для заявителей оценки качества выполненных работ;

- создать на портале рейтинги пользователей и исполнителей;

- создать возможность отправить обращение на доработку, если исполнение обращения заявителя устраивает не в полной мере;

- создать дополнительные меры поддержки самых активных пользователей, в виде грамот или недорогостоящих подарков.

В настоящее время краудсорсинг в региональных и местных органах власти в полной мере свой потенциал не реализовал. Однако, относительно успешные практики применения краудсорсинга уже имеются, что наталкивает на мысль, что при наличии желания и, главное, возможностей данная технология продуктивно и максимально результативно будет внедрена в процесс управления. Краудсорсинг выступает в качестве инструмента для сотрудничества и кооперации власти и общества для решения общих задач, что является прекрасным шагом на пути к формированию доверительных, партнёрских отношений в государстве, исключающих социальное напряжение.

Статья подготовлена в рамках исследования, финансируемого за счет гранта Президента Российской Федерации для государственной поддержки молодых российских ученых МД-855.2020.6 «Мобилизация и демобилизация в современных практиках протестной активности».

\section{Литература}

[1] Hemer J. A snapshot on crowdfunding // The Open Access Publication Server of the ZBW. Karlsruhe. 2011. № 2. P. $11-22$.

[2] Vukovic, M. Crowdsourcing for enterprises // Computer Society. 2009. P. 686-692.

[3] Kuppuswamy B., BayusB.L. Crowdfunding Creative Ideas: The Dynamics of Project Backers in Kickstarter // UNC Kenan-Flagler Research Paper. 2015. №1. P. 20-43.

[4] Быхтин О.В. Мотивация к участию в краудсорсинговых проектах // Научный результат. Социология и управление. 2014. №1. С.46-50.

[5] Лобова С.В., Долженко Р.А. Направления использования краудсорсинга для решения государственных и общественных задач в регионе // Рег. экон.: теория и практика. 2016. № 2. С. 135-148.

[6] Мирошниченко И. В. Модернизационный потенциал краудсорсинга в современной публичной политике: российский опыт и зарубежные практики // Проблемный анализ и государственно-управленческое проектирование. 2011. Т. 4, № 6. С. 31-39.

[7] Сапрыка В.А. Интерактивная модель разработки и реализации социальноэкономических проектов и программ межрегионального приграничного сотрудничества // Региональная экономика. 2010. №47. С. 2-5.

[8] Гайдукова Г.Н. Краудсорсинговый потенциал и барьеры его использования в практике муниципального управления // Управление городом: теория и практика. 2014. №2(13). C. 84-89.

[9] Патаракин Е.Д. Продвижение социальных инноваций через общественное конструирование документов // Образовательные технологии и общество (Educational Technology \& Society). 2012. № 2 (15). C. 517-535.

[10] Нестик Т.А. Краудсорсинг как модель управления знаниями: социальнопсихологические особенности и ограничения // Экономические стратегии. 2014. № 67. C. 170-174. 
[11]Коган Е. Краудсорсинг как фактор репутации // Проблемы теории и практики управления. 2012. №1. С. 90-94.

[12] Чугунов А.В. Электронное участие как канал обратной связи власти и граждан: проблемы институционализации // Азимут научных исследований: экономика и управление. 2016. Т.5, № 4(17). С. 453-459.

[13]Чугунов А.В. Электронное участие в контексте трансформации концепции демократии // Управленческое консультирование. 2017. № 8(104). С. 14-20.

[14]Путин: Цифровые платформы «обратной связи» нужно создать во всех субъектах России // Новости mail.ru. 2020. URL: https://news.mail.ru/politics/40400788/?frommail=1 (дата обращения: 08.02.2020).

[15] «Делаем вместе!» // Официальный сайт «Делаем вместе!». URL: https://delaem.vmeste76.ru/ (дата обращения: 01.02.2020).

[16] Открытая Казань // Официальный сайт «Открытая Казань». URL: https://open.kzn.ru/ (дата обращения: 01.02.2020).

[17]Добродел // Официальный сайт «Добродел». URL: https://dobrodel.mosreg.ru/ (дата обращения: 01.02.2020).

[18]Сделай Орёл лучше // Официальный сайт «Сделай Орёл лучше». URL: https:// сделайореллучше.рф (дата обращения: 01.02.2020).

[19] Активный гражданин республики Бурятия // Официальный сайт «Активный гражданин республики Бурятия». URL: https:/voting.govrb.ru/ (дата обращения: 01.02.2020).

[20]Портал «Наш Санкт-Петербург» // Официальный сайт «Наш Санкт-Петербург». URL: https://gorod.gov.spb.ru/ (дата обращения: 01.02.2020).

[21] Народная экспертиза // Официальный сайт «Народная экспертиза». URL: https://narodexpert.ru/ (дата обращения: 01.02.2020).

[22] Открытый регион Хабаровского края // Официальный сайт «Открытый регион Хабаровского края». URL: https://golos27.ru/\#/main (дата обращения: 01.02.2020).

[23] Действуем вместе // Официальный сайт «Действуем вместе». URL: https://vmeste46.ru/ (дата обращения: 01.02.2020).

[24]Наш дом - Рязань // Официальный сайт «Наш дом - Рязань». URL: http:// нашдом62.pф/ryazan/coms/ (дата обращения: 01.02.2020).

\section{Crowdsourcing Sites of Regional and Municipal Authorities}

\section{O. Komarov, A. Sokolov}

\section{P.G. Demidov Yaroslavl State University}

In modern realities, there is a growing need to establishing dialogue between the government and civil society, increasing the degree of participation of citizens in state management activity. Internet is the optimal channel for establishing such interaction. Crowdsourcing platforms can play a special role in this interaction which can demonstrating the interests of society, identifying and immediately solving existing problems, as well as contributing citizens attraction in the process of preparing and decision-making. In the context of increasing protest moods in the Russian Federation, the productive realization of crowdsourcing campaigns can reduce social intensity in society and help reduce the involvement of citizens in protests and demobilization. The authors formed a system of criteria for evaluating these sites, which allows identifying the features of their functioning and evaluating theirs effectiveness. Among the criteria can note the functionality of the crowdsourcing platform, its attendance and activity of use, the possibility of ranking users, the degree of interactivity, etc. The article also presents an analysis of the largest regional platforms aimed at demonstrating citizens the most pressing problems for them. The 
authors also presented an assessment of the results of the authorities` work with the proposals of citizens.

Keywords: crowdsourcing, regional and local authorities, project, communication, initiatives, appeals, Internet

Reference for citation: Komarov O., Sokolov A. Crowdsourcing Sites of Regional and Municipal Authorities // The State and Citizens in the Electronic Environment. Vol. 4 (Proceedings of the XXIII International Joint Scientific Conference «Internet and Modern Society», IMS-2020, St. Petersburg, June 17-20, 2020). - St. Petersburg: ITMO University, 2020. P. 73-85. DOI: $10.17586 / 2541-979 X-4-73-85$

\section{Reference}

[1] Hemer J. A snapshot on crowdfunding // The Open Access Publication Server of the ZBW. Karlsruhe. 2011. № 2. P. $11-22$.

[2] Vukovic, M. Crowdsourcing for enterprises // Computer Society. 2009. P. 686-692.

[3] Kuppuswamy B., BayusB.L. Crowdfunding Creative Ideas: The Dynamics of Project Backers in Kickstarter // UNC Kenan-Flagler Research Paper. 2015. №1. P. 20 - 43.

[4] Byhtin O.V. Motivaciya k uchastiyu v kraudsorsingovyh proektah // Nauchnyj rezul'tat. Sociologiya i upravlenie. 2014. №1. S. 46-50. (in Russian).

[5] Lobova S.V., Dolzhenko R.A. Napravleniya ispol'zovaniya kraudsorsinga dlya resheniya gosudarstvennyh i obshchestvennyh zadach v regione // Reg. ekon.: teoriya i praktika. 2016. № 2. S. 135-148. (in Russian).

[6] Miroshnichenko I. V. Modernizacionnyj potencial kraudsorsinga v sovremennoj publichnoj politike: rossijskij opyt i zarubezhnye praktiki // Problemnyj analiz i gosudarstvennoupravlencheskoe proektirovanie. 2011. T. 4, № 6. S. 31-39. (in Russian).

[7] Sapryka V.A. Interaktivnaya model' razrabotki i realizacii social'no-ekonomicheskih proektov i programm mezhregional'nogo prigranichnogo sotrudnichestva // Regional'naya ekonomika. 2010. №47. S. 2-5. (in Russian).

[8] Gajdukova G.N. Kraudsorsingovyj potencial i bar'ery ego ispol'zovaniya v praktike municipal'nogo upravleniya // Upravlenie gorodom: teoriya i praktika. 2014. №2(13). S. 84-89. (in Russian).

[9] Patarakin E.D. Prodvizhenie social'nyh innovacij cherez obshchestvennoe konstruirovanie dokumentov // Obrazovatel'nye tekhnologii i obshchestvo (Educational Technology \& Society). 2012. № 2 (15). S. 517-535. (in Russian).

[10] Nestik T.A. Kraudsorsing kak model' upravleniya znaniyami: social'no-psihologicheskie osobennosti i ogranicheniya // Ekonomicheskie strategii. 2014. № 6-7. S. 170-174. (in Russian).

[11] Kogan E. Kraudsorsing kak faktor reputacii // Problemy teorii i praktiki upravleniya. 2012. №1. S. 90-94. (in Russian).

[12] Chugunov A.V. Elektronnoe uchastie kak kanal obratnoj svyazi vlasti i grazhdan: problemy institucionalizacii // Azimut nauchnyh issledovanij: ekonomika i upravlenie. 2016. T.5, № 4(17). S. 453- 459. (in Russian).

[13] Chugunov A.V. Elektronnoe uchastie v kontekste transformacii koncepcii demokratii // Upravlencheskoe konsul'tirovanie. 2017. № 8(104). S. 14-20. (in Russian).

[14] Putin: Cifrovye platformy «obratnoj svyazi» nuzhno sozdat' vo vsekh sub"ektah Rossii //Novosti mail.ru. 2020. URL: https://news.mail.ru/politics/40400788/? frommail=1 (data obrashcheniya: 08.02.2020). (in Russian).

[15] «Delaem vmeste!» // Oficial'nyj sajt «Delaem vmeste!». URL: https:// delaem.vmeste76.ru/(data obrashcheniya: 01.02.2020). (in Russian).

[16] Otkrytaya Kazan' // Oficial'nyj sajt «Otkrytaya Kazan'». URL: https://open.kzn.ru/ (data obrashcheniya: 01.02.2020). (in Russian). 
[17]Dobrodel // Oficial'nyj sajt «Dobrodel». URL: https://dobrodel.mosreg.ru/ (data obrashcheniya: 01.02.2020). (in Russian).

[18] Sdelaj Oryol luchshe // Oficial'nyj sajt «Sdelaj Oryol luchshe». URL: https://xn-80ahdbawmda1awf0b6cp.xn--p1ai/ (data obrashcheniya: 01.02.2020). (in Russian).

[19] Aktivnyj grazhdanin respubliki Buryatiya // Oficial'nyj sajt «Aktivnyj grazhdanin respubliki Buryatiya». URL: https://voting.govrb.ru/ (data obrashcheniya: 01.02.2020). (in Russian).

[20]Portal «Nash Sankt-Peterburg» // Oficial'nyj sajt «Nash Sankt-Peterburg». URL: https://gorod.gov.spb.ru/ (data obrashcheniya: 01.02.2020). (in Russian).

[21] Narodnaya ekspertiza // Oficial'nyj sajt «Narodnaya ekspertiza». URL: https://narodexpert.ru/ (data obrashcheniya: 01.02.2020). (in Russian).

[22] Otkrytyj region Habarovskogo kraya // Oficial'nyj sajt «Otkrytyj region Habarovskogo kraya». URL: https://golos27.ru/\#/main (data obrashcheniya: 01.02.2020). (in Russian).

[23] Dejstvuem vmeste // Oficial'nyj sajt «Dejstvuem vmeste». URL: https://vmeste46.ru/ (data obrashcheniya: 01.02.2020). (in Russian).

[24]Nash dom - Ryazan' // Oficial'nyj sajt «Nash dom - Ryazan'». URL: http://xn--626kcq4bdj2f.xn--p1ai/ryazan/coms/ (data obrashcheniya: 01.02.2020). (in Russian). 